\title{
Evaluation of Agricultural Output Efficiency Based on DEA Model-Taking Xinjiang as an Example
}

\author{
Li Feng \\ Shaanxi Normal University \\ Shaanxi, China \\ 2482894098@qq.com
}

\begin{abstract}
In this paper, the CCR model in the data envelopment analysis model was used to calculate and analyze agricultural technology efficiency, pure technical efficiency, and scale efficiency in various regions of Xinjiang from 1994 to 2013. The efficiency of agricultural production in various regions of Xinjiang has improved rapidly. The efficiency is relatively high and relatively stable; the efficiency value between regions is quite different and so on. It is proposed to further improve agricultural production efficiency in various regions of Xinjiang by constructing agricultural economic cooperation organizations, improving the scientific nature of agricultural production, and making use of comparative advantages.
\end{abstract}

Keywords-DEA model; Agricultural output efficiency; Technical efficiency; Scale efficiency

\section{INTRODUCTION}

Xinjiang is dominated by agriculture, and because it is located in the northwestern border of China, the natural environment is harsh. On the other hand, the unique human and geographical environment in Xinjiang determines the key role of the smooth development of Xinjiang in the stability and stability of our society as a whole. Agricultural production is the basis for ensuring basic living needs and maintaining social stability. Due to the constraints of population pressure and limited arable land resources, improving the output efficiency of agriculture through intensive agricultural development is an important way to increase agricultural output in Xinjiang. Therefore, it is of far-reaching significance to study Xinjiang's agricultural production efficiency and its changing trend, analyze its causes of change, and then propose targeted policy recommendations.

At present, the domestic research on the measurement of agricultural production efficiency is mainly through the measurement model. The commonly used methods are Data Envelopment Analysis (DEA) and Stochastic Frontier Analysis (SFA). Some scholars also use Malmquist index analysis method to study agricultural production efficiency from the perspective of agricultural total factor productivity. For example, Yu Jianbin (2008) [1], Zheng Xundang (2009)[2] and Jia Yuzhi (2013)[3] adopted the SFA method. This method can directly measure the technical efficiency of agricultural production and its influencing factors. However, the disadvantage of SFA is that it only applies to the situation of one output, and the model needs to presume the form of the production function in advance.
The Malmquist index analysis method is mainly used to measure total factor productivity and decompose technical efficiency values. For instance, Li Zhaotang (2008) [4] and Deng Zongbing (2010) [5] used this method to study the efficiency of China's agricultural production technology and its impact on total factor productivity. It was concluded that changes in technological efficiency would have an adverse effect on the growth of China's agricultural total factor productivity. Wu Fengjiao et al. (2011)[6] Based on the research methods of various scholars, this paper proposes to use the DEA method to measure the agricultural production efficiency in Xinjiang from 1994 to 2013.

\section{A THEORETICAL MODEL}

Data Envelopment Analysis (DEA) was proposed by A.Charnes and W.W.Cooper in 1978. Based on relative efficiency, DEA uses convex analysis and linear programming as tools to identify effective production frontiers and project each type of decision unit (DMU) onto the production frontier of the DEA, by comparing the DMU's departure from the DEA frontier. Degrees to evaluate their relative effectiveness. The CCR model is their first model to study the "production department" at the same time as "scale effective" and "technical effective." The BCC model changes the CRS model's assumption of scale-invariant (CRS) to variable-variable-return (VRS), and decomposes the technical efficiency into a product of pure technical efficiency and scale efficiency to measure the technical efficiency and scale efficiency of the DMU.

There are $n \operatorname{DMUj}(j=1,2, \ldots, n)$, each DMUj has $m$ input, $s$ output, respectively expressed as $\mathrm{Xj}=(\mathrm{x} 1 \mathrm{j}, \mathrm{x} 1 \mathrm{j}, \ldots, \mathrm{x} 1 \mathrm{j}) \mathrm{T}>0, \mathrm{Yj}=$ $(y 1 \mathrm{j}, \mathrm{y} 1 \mathrm{j}, \ldots, \mathrm{y} 1 \mathrm{j}) \mathrm{T}>0$. For any decision unit, the input-directed dual-form BCC model can be expressed as:

$\min \theta$

$$
\text { s.t. }\left\{\begin{array}{c}
\sum_{j=1}^{n} \lambda_{i j} x_{j} \leq \theta x_{i 0}, \quad i=1, \ldots, m \\
\sum_{j=1}^{n} \lambda_{r j} y_{j} \geq \theta y_{r 0}, \quad r=1, \ldots, s \\
\sum_{j=1}^{n} \lambda_{j}=1 \\
\lambda_{j} \geq 0
\end{array}\right.
$$

Compared with the parametric model, the DEA model has the following advantages: (1) DEA does not need to formulate a specific input-output production function form in advance. (2) The efficiency of the DEA measurement unit is not affected by the selected input and output indicator data units and input- 
output weights. (3) DEA can achieve differential analysis, sensitivity analysis, and efficiency analysis.

\section{SAMPle Data AND EVAluation INDEX SELECTION}

Based on the availability of data and the continuous comparability of data, this article selects the actual output value of agriculture, forestry, animal husbandry and fishery in each region as an output indicator. This value was obtained by using the 1995 agricultural product price index as the base period.
Input Factors Selection Agricultural labor force (X1) and planting area (X5) represent labor input factors and land input factors respectively, total agricultural machinery power (X2), irrigated area (X4), and draught animals (X6) as input for agricultural capital, and fertilizer usage (X3) (X3) as a substitution variable for intermediate inputs. The data comes from the "China Statistical Yearbook" and "Xinjiang Statistical Yearbook". The criteria for the selection of various indicators are shown in Table 1.

TABLE I EXPLANATION OF INPUT AND OUTPUT INDICATORS

\begin{tabular}{|c|c|c|}
\hline Variable Name & Unit & Description \\
\hline Agricultural output (Y) & 100 million & $\begin{array}{l}\text { in actual output value of agriculture, forestry, animal } \\
\text { husbandry and fishery }\end{array}$ \\
\hline Agricultural labor force (X1) & Millions Population & at the end of the rural labor force mainly engaged in agriculture \\
\hline $\begin{array}{l}\text { Total power of agricultural } \\
\text { machinery (X2) }\end{array}$ & Million kilowatts & $\begin{array}{l}\text { The end of the total number of major agricultural machinery } \\
\text { power }\end{array}$ \\
\hline $\begin{array}{l}\text { Fertilizer application amount } \\
\text { (X3) }\end{array}$ & 10,000 tons & $\begin{array}{l}\text { The amount of chemical fertilizer actually used for agricultural } \\
\text { production during the year }\end{array}$ \\
\hline Irrigation area $(\mathrm{X} 4)$ & Thousands of hectares & Effective irrigation area of crops \\
\hline Sown area $(\mathrm{X} 5)$ & Thousands of hectares & Crop sown area \\
\hline Livestock (X6) & 10000 & heads of livestock at the end of the year \\
\hline
\end{tabular}

According to the DEA model, the agricultural production technology efficiency, pure technical efficiency, and scale efficiency of the country and Xinjiang regions from 1994 to 2013 were calculated using deap2.1 software. As shown in the table below (taking into account the comparability of the data, the average efficiency value of Xinjiang compared with the efficiency values of North and South East Xinjiang is the average of the efficiency values of various regions in Xinjiang, and the average efficiency value of Xinjiang compared with the states of Xinjiang is put into production. The calculation of output efficiency values: Due to the vast territory of Xinjiang and the differences in regional climatic conditions, agricultural production techniques, and living production habits, resulting in inconsistent agricultural production efficiency in different regions, the efficiency values of agricultural production in Xinjiang were analyzed in different regions.

\section{RESULT}

\section{A. Overall analysis of efficiency values}

The efficiency values of various regions in Xinjiang

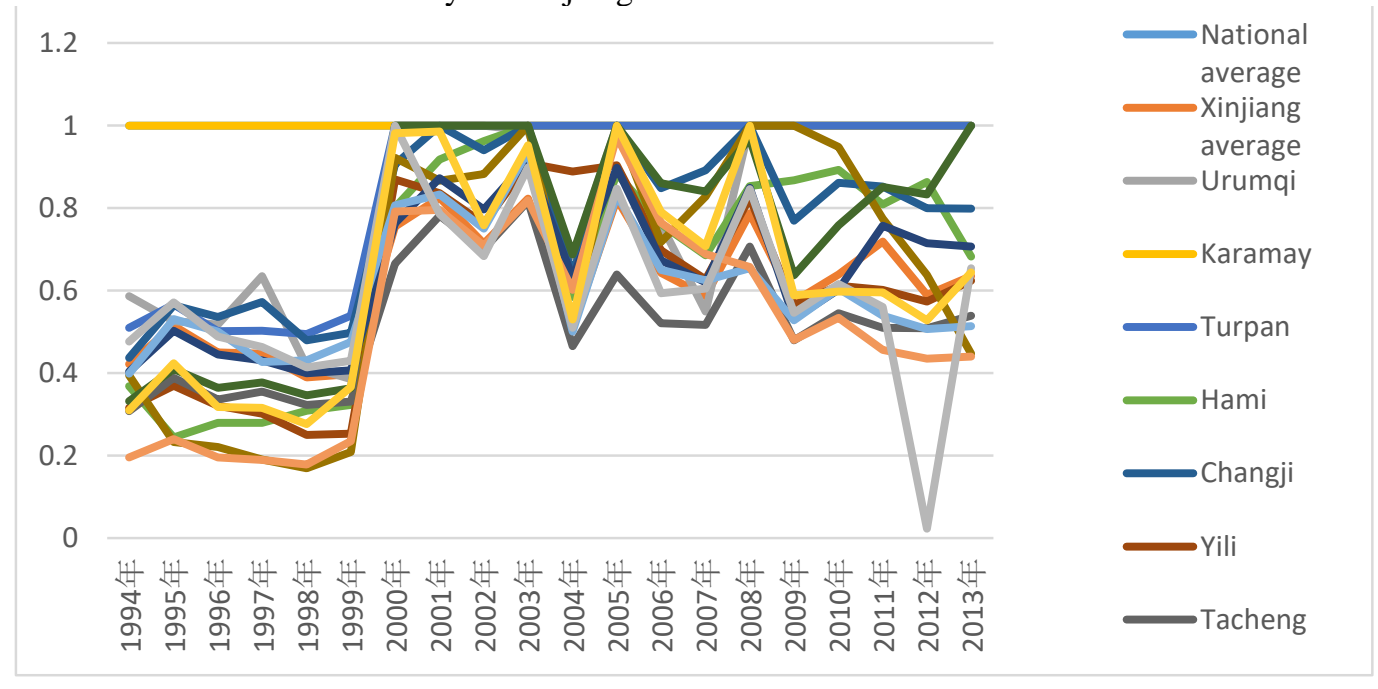

Fig. 1 The efficiency values of various regions in Xinjiang 


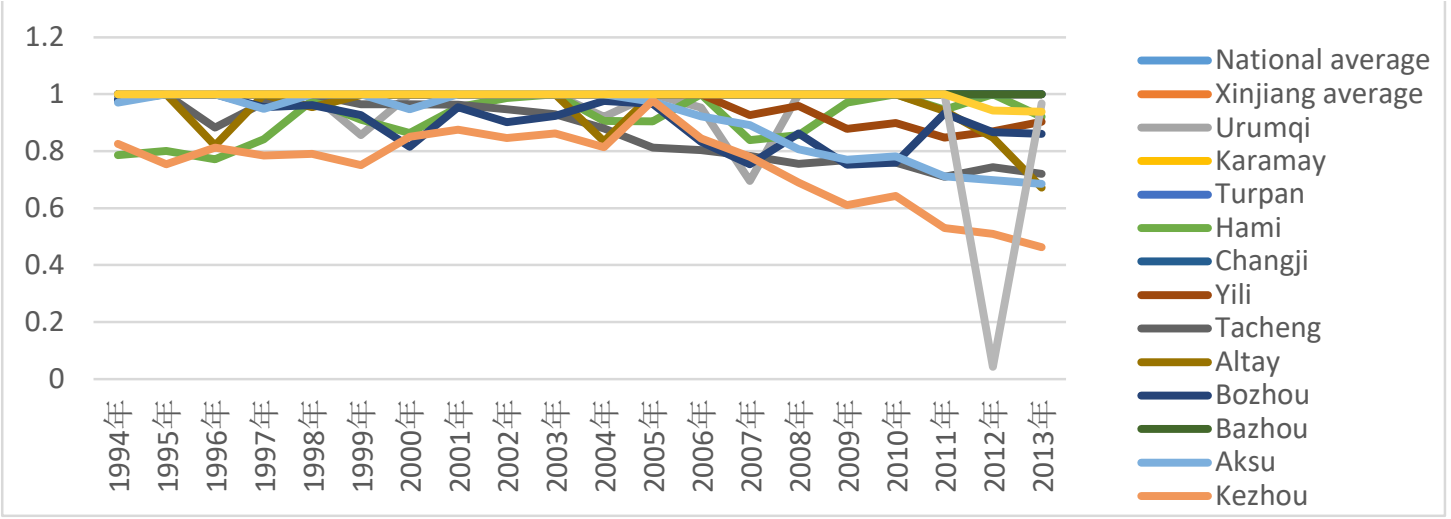

Fig. 2 The pure efficiency values of various regions in Xinjiang

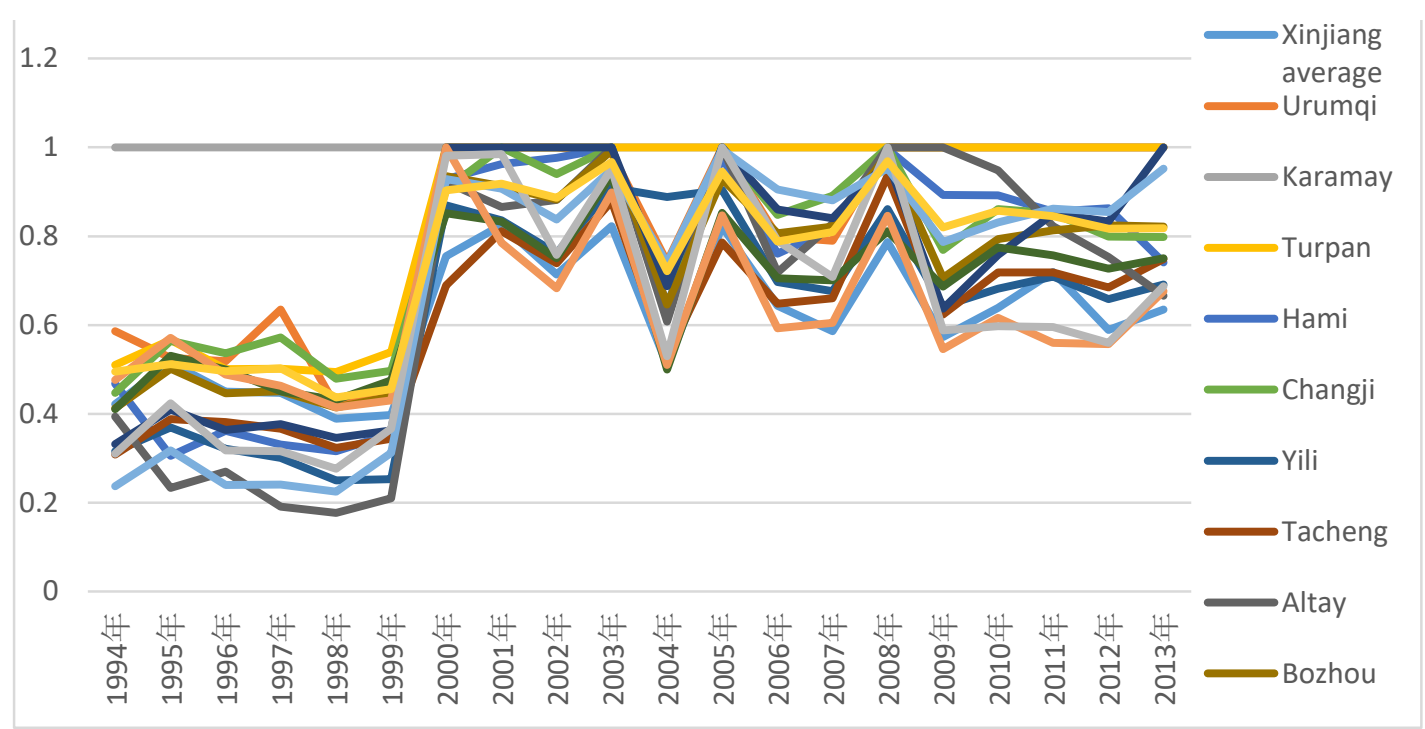

Fig. 3 The scale efficiency values of various regions in Xinjiang

As can be seen from Figures 1, 2, and 3, (1) Compared with Xinjiang and its regions, the national technical efficiency, pure technical efficiency, and scale efficiency value have been at the frontier of efficiency for the past 22 years. However, fluctuations in efficiency values in various regions of Xinjiang are relatively large. From 1994 to 2009, the volatility and fluctuation trend of each efficiency value in each region of Xinjiang were relatively consistent, After 2009, the volatility of efficiency values between regions showed a significant difference. (2) As can be seen from the following three graphs, the changes in technical efficiency and scale efficiency of various regions in Xinjiang are relatively close, and the trend of pure technical efficiency has not changed much in the past 22 years, due to technical efficiency = purely technical efficiency * scale efficiency. Therefore, it can be concluded that the changes in the technical output of agricultural output in various regions of Xinjiang are mainly caused by changes in scale efficiency.

\section{B. Analysis of Technical Efficiency}

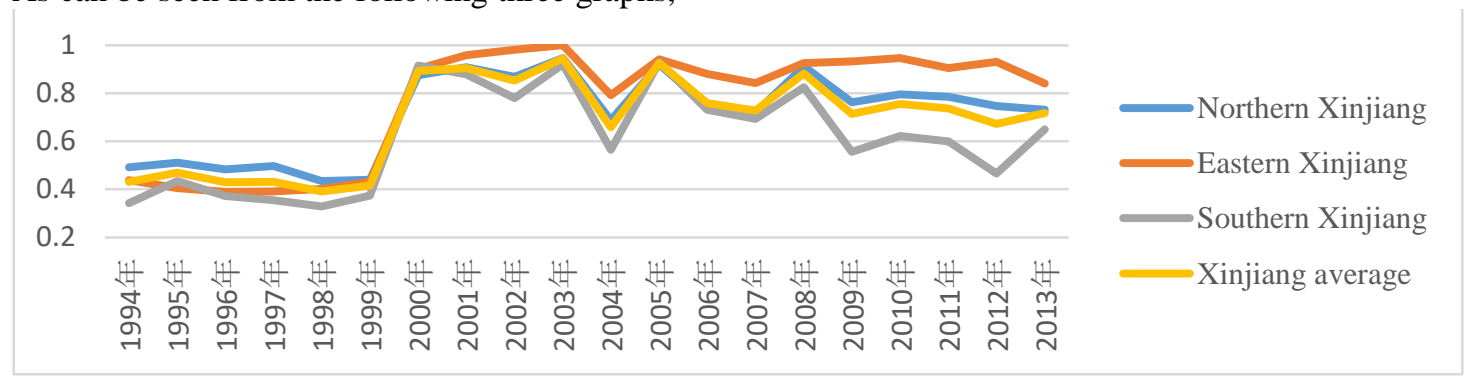

Fig. 4 Technical efficiency in North and South East Xinjiang 


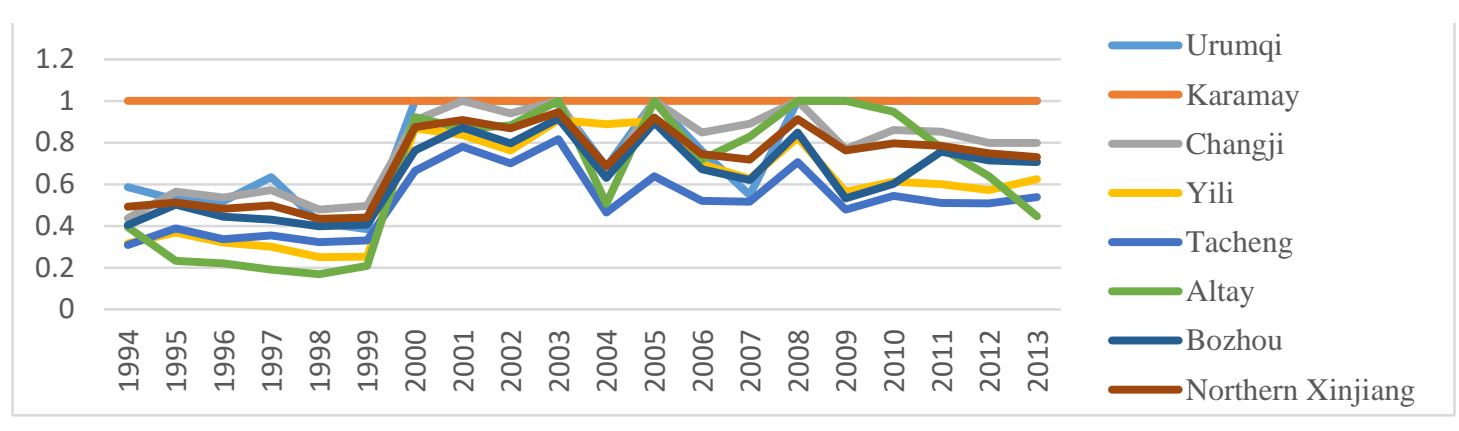

Fig. 5 Technological Efficiency in Northern and Southern Regions

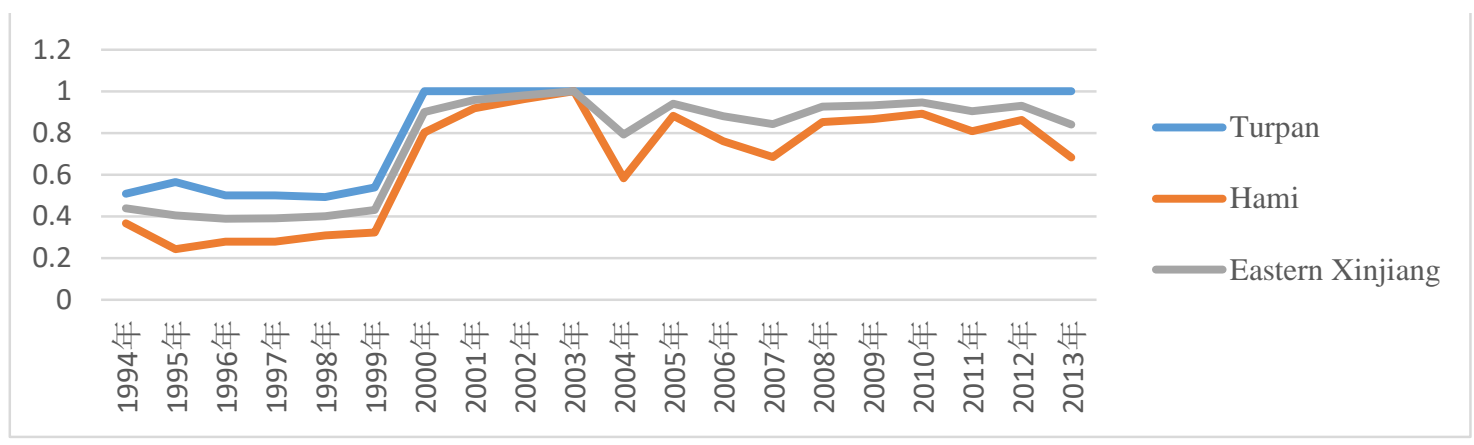

Fig. 6 Technical Efficiency in Eastern Xinjiang

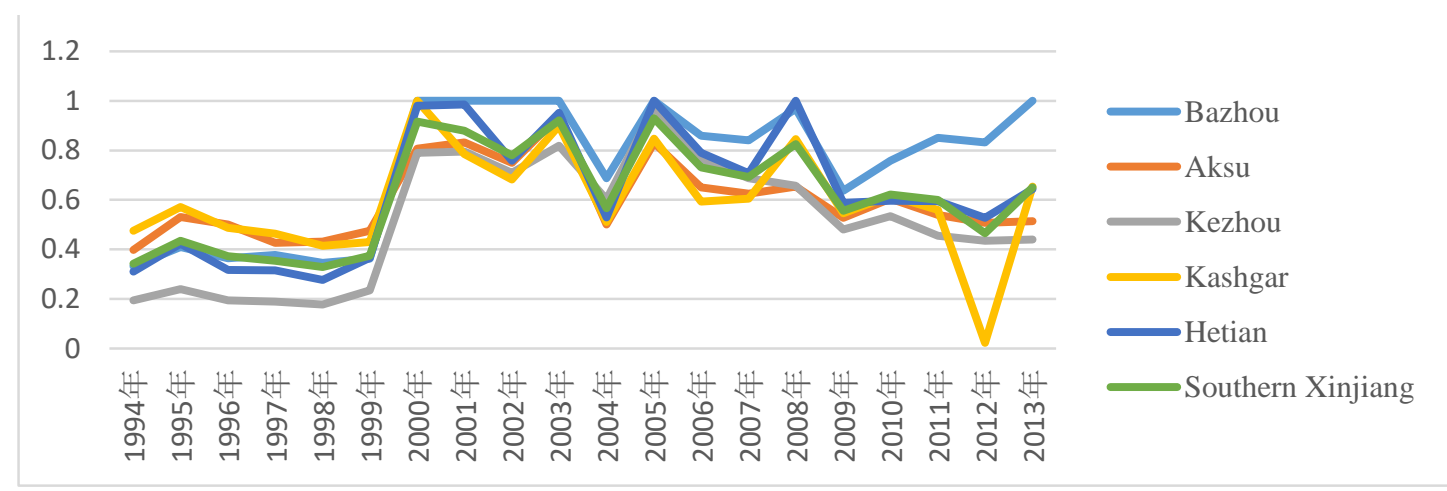

Fig. 7 Technical Efficiency in Southern Xinjiang

From the calculation results in Figure 4, it can be seen that in the past 22 years, the agricultural production efficiency in Xinjiang and the eastern and southern Xinjiang has fluctuated greatly, but the direction and extent of fluctuations in each region are relatively consistent. As a turning point, 2000, the efficiency value has greatly increased from 0.4 to 0.9 . From 2000 to 2013, the efficiency value as a whole showed a downward trend. The technical output value of agricultural output in Dongjiang was the largest, floating around 0.9, and the technical efficiency value of the northern Xinjiang was similar. The average level in Xinjiang is close to 0.7-0.9. The technical efficiency in southern Xinjiang is lower than the average level in Xinjiang, and the efficiency value is falling faster.

The efficiency values of the northern and southern regions also experienced the process of falling first, then rising and then falling. From the perspective of agricultural production in the past 14 years, Urumqi's agricultural production technology efficiency value is located at the frontline of production, followed by Altay and Changji Autonomous Prefecture.
Between 0.8-1, again, the average technical efficiency level of Karamay City, Bozhou, and North Xinjiang dropped from 0.6 to 0.9 , and the agricultural production technology of Tacheng District was the lowest, which was near 0.6. The efficiency of agricultural production technology in all regions of eastern Xinjiang has generally risen in fluctuations. From the past 14 years, the efficiency of agricultural production technology in the Turpan region has been at the frontier of production, and the agricultural production technology efficiency in the Hami region. Slightly lower than the average level in eastern Xinjiang, it floats up and down at 0.8. After the technical efficiency of agricultural production in various regions of southern Xinjiang has increased substantially since 2000 , the overall trend has been declining in the past 14 years (2000-2013). The agricultural production technology in Bazhou and Hetian regions is higher than the average level in Xinjiang, Aksu, and Kezhou. The technical efficiency of the Kashgar region is slightly lower than the average level in southern Xinjiang. 


\section{Pure technical efficiency analysis}

The level of purely technical efficiency of agricultural production in North and South East Xinjiang has little difference and fluctuates between 0.9-1. (Due to space limitations, the form is not listed in the text. If necessary, the author can ask for the form.)Overall, the average technical efficiency of Dongjiang has slowly increased in the past 20 years, while the Northeastern Xinjiang and the entire Xinjiang region It has declined. In particular, the purely technical efficiency of agricultural production dropped significantly by 0.3 from 2008 to 2012, and then rose to 0.8 .

As far as the northern Xinjiang area is concerned, the pure technical efficiency of Changji Autonomous Prefecture has been at the frontier of pure technical efficiency, and the individual year in the Altay region has fluctuated, but overall the pure technical efficiency value is at the frontier, and the pure technical efficiency of Tacheng District is declining. The drop was 0.3 , and the drop in pure technical efficiency in other areas was controlled within 0.1. As far as the East Xinjiang area is concerned, Turpan has always been at the forefront of purely technical efficiency, while Hami has continued to rise, and its purely technical efficiency value has also reached one. Judging from the southern Xinjiang region, Bazhou, Kashgar and Hetian are at the frontier, with 2005 as the time node. Prior to 2005, the approximate number in the Aksu region was 1; after 2005, the number dropped to near 0.8, and the Kezhou region in 2005. Year-on-year fluctuates around 0.8, after 2005 it drops to 0.5.

\section{Analysis of the scale of income}

The issue of economies of scale in agricultural production in the Xinjiang region (Due to space limitations, the diagrams are abbreviated and, if necessary, can be requested from the author). There are few differences in the scale of agricultural production in Xinjiang. In the past 20 years, the average national level has shown that the scale returns have not changed. In individual years in Xinjiang, the scale returns are unchanged. In general, the various regions in Xinjiang are in different stages of diminishing returns. This does not absolutely mean that the current scale of agriculture in Xinjiang is too large. The reason for the decline in the scale of returns may be due to too little investment in resources, resulting in a mismatch between input and scale, or due to the inefficient use of inputs.

\section{CONCLUSION}

After nearly 20 years of development, compared with the national average, the agricultural technology efficiency in various regions of Xinjiang has been greatly improved, and has remained relatively stable at higher levels of efficiency. This fully affirmed the effectiveness of the state's supportive policies for agricultural production and the promotion of agricultural production technology to promote the efficiency of agricultural production. However, it should still be noted that the efficiency of agricultural production in most regions of Xinjiang is lower than the national average, and there is still much room for seeking greater efficiency values on the basis of maintaining the existing higher level of efficiency values.

The differences between regions are worth paying attention to. The efficiency of eastern Xinjiang is higher than that of northern Xinjiang, while the efficiency values of southern
Xinjiang are relatively at the lowest level. One of the more obvious reasons is that precipitation in northern Xinjiang is more abundant than in southern Xinjiang. . There are also large differences in efficiency values between different regions in different regions of the South and North. Judging from the continuous data from 2000 to 2014, the relative positions of various efficiency values in various regions show a solid trend, that is, low efficiency values have always been inefficient, and high-efficiency values have been at high efficiency. This shows that each region is not sufficiently efficient. Recognizing the key reasons for inefficiency and the inability to use regional comparative advantages to enhance the efficiency of agricultural production in the region. Through in-depth research on agricultural production, we have explored the advantages of experience in areas with higher levels of efficiency and provided guidance and guidance for regions with low efficiency. This is also an important method for narrowing regional differences and promoting balanced development among regions.

Through the above analysis, this paper proposes several policy suggestions for improving the agricultural production efficiency in Xinjiang in light of the current status of agricultural development in Xinjiang.

\section{E. Building an Agricultural Economic Cooperation Organization}

The scale of land in Xinjiang is large and the scale and efficiency of Xinjiang and its various states are high. It is expected that the adjustment will be optimized to achieve the optimum. According to the experience of developed countries, the emergence of agricultural cooperatives is an inevitable choice for agricultural-scale production. Various forms of agricultural economic cooperation organizations can be developed in Xinjiang to transform the small-scale production of households into social-scale production. The agricultural cooperatives can be incorporated into the traditional order agriculture model of "company + farmer households", through the Agricultural Economic Cooperatives, Coordinate and promote the production of agricultural households according to market needs, and realize the sustainable development of the agricultural scale effect.

\section{$F$. Improve the scientific nature of agricultural production}

With limited resources, improving the efficiency of resource use is the key to improving the efficiency of agricultural production. The development of agricultural technology has played an important role in agricultural production. Therefore, by improving the level of science popularization in rural areas, scientifc methods are used to guide agricultural production, and the efficiency of agricultural machinery power, chemical fertilizers, and pesticides are used to increase the production efficiency of land. 


\section{G. Play a comparative advantage}

Due to the regional economic, social, and cultural differences, the advantageous agricultural production projects vary from region to region, and each region fully utilizes its own comparative advantages to achieve differentiated competition, which is an effective way to increase agricultural output and efficiency, and to increase farmers' income. The governments of all regions can invite experts in agricultural production to conduct on-site inspections and fully grasp the advantages and disadvantages of agricultural development in the region. At the same time, we must make full use of the agricultural production and management models in the frontier areas of agricultural production efficiency for our own use. However, it must not be applied in a rigid manner. It must be adapted to local conditions and developed scientifically.

\section{REFERENCES}

[1] YU Jianbin, LI Dasheng. Analysis of Technical Efficiency and Influencing Factors of Agricultural Production in China [J]. Statistics and Decision, 2008(14):83-86. (In Chinese)

[2] Zheng XG. Analysis of China's agricultural production technology efficiency and its influencing factors [J]. Statistics and Decision, 2009(23): 102-104. (In Chinese)

[3] Jia Yuzhi, Guo Yajun, Xu Li. Measurement and Analysis of Technical Progress Rate of Wheat Production in China: Based on Stochastic Frontier Analysis Method [J].Guangdong Agricultural Sciences, 2013,40(02):192-196. (In Chinese)

[4] Li Lutang, Xue Jiliang. Research on the Trend of Agricultural Productivity Growth in China: 1980 2006[J]. Journal of Shanghai University of Finance and Economics, 2008(04):76-83. (In Chinese)

[5] Deng Zongbing. Research on the Growth of Total Factor Productivity in China's Agriculture and Its Influencing Factors [D]. Southwest University, 2010. (In Chinese)

[6] WU Fengjiao, CHEN Yinzhong. Comparative Study of Agricultural Productivity across the Taiwan Straits: Malmquist Index Method Based on DEA [J]. Taiwan Research, 2011(6): 57-65. (In Chinese) 